\section{Psychiatry and the private sector}

DeAR Sirs

I wonder what "good deal" Desmond Kelly is addressing in his comments concerning psychiatry and the private sector (Psychiatric Bulletin, September 1989, 13, 510). Of course it is possible to treat NHS and private patients in the same surroundings. Surely the issue which Dr Kelly refuses to address is that of why NHS patients cannot be treated within the NHS. It is indeed impressive that only one Camberwell patient absconded. It is adequate confirmation of the superior levels of resources possessed by the private sector hospitals. Should we be slapping the Priory Hospital on the back for being able to manage such patients? It is after all what a psychiatric hospital, in whatever sector, is supposed to do!

It is essential that we are not seduced by amusing anecdotes and respectable statistics into acceptance of the notion that basic NHS facilities can be reasonably provided by the private sector. That is an argument which can only undermine the continuing wellbeing of a comprehensive National Health Service. I am glad that the Priory Hospital provides a good service to patients and it is right for Desmond Kelly to be able to inform us of that fact. It is wrong that both he and the College are not addressing the inadequacy of service provision in Camberwell as the real priority.

The Belgrave Department of Child and Family

RICHARD EYRE Psychiatry

King's College Hospital

London SE5 9RS

\section{Section 117, Mental Health Act, 1983}

\section{DeAr Sirs}

I am a catchment area psychiatrist. I normally transfer patients to another psychiatrist if I know they are leaving my catchment area. I accept other patients who are moving in. My patients tend to move about, round Birmingham and across the boundary into the Black Country. I was interested, therefore, in seeing what had happened to my Section 117 patients whom I had accumulated since 1983 to the present time.

Total number

Still in my catchment area

In day care with me

In my out-patient clinics

In my in-patient bed

Out of touch with NHS/Social Services

(Two have firmly rejected any kind of followup from me or social worker or community psychiatric nurse. One has Korsakov's psychosis and is resident in an old people's home)

Number who have died

10 Died of natural causes

Suicides

(Of these, one was psychotic and a very heavy drinker, who had walked out of treatment and had not been seen for some time. The other had been transferred to another psychiatrist and was under treatment at the time of death.)

Number who have been transferred to another psychiatrist by dint of moving home

Even keeping track of this small number of patients is difficult. My experience shows how mobile this group of patients is. The task of tracking down other patients who need long-term follow-up is just as daunting.

Should I consider employing the local Court Oak Road Irregulars, or should I now hold jumble sales in order to purchase the computer we cannot afford in order to keep everyone under surveillance?

P. A. J. GOODYEAR

Yewcroft Mental Health Resource Centre

Court Oak Road

Harborne

Birmingham B17 9AB

\title{
Health care buzz word generator
}

DeAR SiRS

I was interested to see Dr Platts' contribution (Psychiatric Bulletin, December 1989, 13, 679).

Your readers may be interested to know that there exists a Health Education Jargon Generator, designed by Mike Church of the Scottish Health Education Unit, Edinburgh, and Aron Cronin, of the Health Education Council, London, with due acknowledgements to the New Internationalist.

This Health Education Jargon Generator was published in 1979, at the time of the 10th International Conference on Health Education. Copies are available from The Editor, International Journal of Health Education, 3 rue Voillier, CH-1207, Geneva, Switzerland.

The original Jargon Generator consists of three concentric dials, which you rotate freely to align the words written on them. Phrases that constitute a send-up of the language of Health Education are made up by taking words randomly, and in sequence, from the inner, middle and outer dials of the device, as follows:

Inner dial words coordinated programmed systematic fundamental conventional pragmatic
Middle dial words decision-making planning issue-oriented identified on-going conceptual
Outer dial words outcomes scenarios polarisation attitudes skills models 
Inner dial words conforming functional comprehensive unstructured
Middle dial words socio-economic methodological statistical hypothetical
Outer dial words policies beliefs strategies frameworks

and so on, for a total of 36 words on each dial.

There is no copyright on the Health Education Jargon Generator. As it is simply a bit of fun, and available free of charge, Church \& Cronin probably felt no need for such protection. All the same, they deserve the credit for their work.

PO Box 1415

I. O. AZUONYE

London NW6 $5 Y W$

\section{Reference}

Church, M. \& Cronin, A. (1979) The Health Education Jargon Generator. Geneva: International Journal of Health Education.

\section{Inappropriate language}

\section{DeAR Sirs}

Any attempt by European psychiatrists to understand patterns of emotional distress and treatment with which they are unfamiliar is surely welcome. May I protest, however, at the approach and language adopted by Dr Rands (Psychiatric Bulletin, November $1989,13,622-625$ ) in the account of her trip to Malawi. It is far from clear what sort of information is being communicated through an idiom of "superstitious and jealousy-ridden population"; "shiny black faces"; "the characteristic smell of Malawi sweat"; "frenzied"; "extraordinary"; "essential primaeval rhythm". This is not ethnographic description, it is racist stereotype.

University College \&

ROLAND LitTlEWOOD

\section{Middlesex School of Medicine}

Riding House Street, London WIN 8AA

\section{Miscellany}

\section{New publications}

The Ethnic Minority Health Bulletin is the first information service to cover the mental, physical and social aspects of health care of ethnic minority people in the United Kingdom. The annual subscription is $£ 25$ ( $£ 45$ for two years). Further information: Christine Gardiner, Editor, Ethnic Minority Health Bulletin, Lynfield Mount Hospital, Heights Lane, Bradford, W. Yorks BD9 6DP.

The Arab Journal of Psychiatry is published under the auspices of the Arab Federation of Psychiatrists provisionally in November and May each year. Original papers, reviews, case reports and brief communications in all fields of psychiatry are invited. The annual subscription is $\$ 25$. Further information: Dr Adnan Takriti, Editor, The Arab Journal of Psychiatry, POB 5370, Amman, Jordan.

\section{Reports}

The Report on the Eleventh Year (1 October 1988-30 September 1989) of the Alcohol Research Group is available from the Department of Psychiatry, University of Edinburgh, Kennedy Tower, Morningside Park, Edinburgh EH 10 5HF. It includes information on the Group's Survey of Drinking Habits among Teenagers in England and its project on the Development of Alcohol Education for Schools.

The Annual Report, 1988-1989, of the North West Fellowship for the Support of Schizophrenia Sufferers and Their Families is available from the Fellowship at 46 Allen Street, Warrington, Cheshire WA2 7JB and includes details of the Fellowship's projects. 